\title{
Analysis of Mathematical Thinking Styles through Oral Test for Proving Curvature Theorem
}

\author{
Siti Khoiruli Ummah \\ University of Muhammadiyah Malang \\ khoiruliummah@umm.ac.id
}

\begin{abstract}
The objective of the research was to analyze mathematical thinking style through the oral test to prove the theorem of the curvature. Mathematical thinking style was divided into three: visual thinking styles, analytical thinking styles, and integrated thinking style. The research method used was descriptive using qualitative data. The data were collected through oral test using the recording of interview. Students who have a visual thinking could explain the proof of theorem graphically. Students who have an analytical thinking style used the mathematics symbol to prove the theorem. Students with integrated thinking style could prove a theorem not only draw the proof graphically but also explained the proof orally.
\end{abstract}

Keywords: Mathematical Thinking Styles; Oral Test, Proving Theorem

\section{INTRODUCTION}

Thinking could be done by humans anywhere and anytime. There were many studies about the thought of them i.e. thinking mathematically [1], critical thinking [2], creative thinking [3], systems thinking [4], and others. The thinking ability of each type has characteristic and specific indicators to measure it. Everyone has different thinking ability. It was associated with a person's level of thinking, habits of thinking [5], and thinking styles.

The style was different among individuals. Typically, the style was measured using performance tests where the test was not concerned with the answer right or wrong [6]. In education, there were three terms that were very popular on the word of style i.e. learning style, cognitive style, and thinking style. They were very different review of their activities. However, they have common purpose and have a variety of different ways on the students to process information received, and use the capabilities to process it [7]. Learning styles more described about how students obtain information while thinking styles described how students process the information taken [8]. Thinking styles more accentuated on the processing of information obtained by students through a certain way [9] known by the term "Mindex Theory". The style of thinking is also an option in the usage of each individual capability in processing the information [8]. This was in line with the opinions of Zhang and Sternberg who stated that the style of thinking was how students chose to use his ability of academic performance [10].
Based on The Theory of the Mental Self-Government and Rita Borromeo, known by the term of The Theory of Mathematical Thinking Styles (MTS), thinking styles have two main theories of thinking styles. According to Sternberg, The Theory of the Mental Self-Government is based on the way the community arrangements manage the community activities differently each other [11]. Those different ways in community settings trigger the emergence of thinking style. Sternberg classifies thinking styles into 13 with five dimensions of Mental SelfGovernment [12]-[13]. The dimensions are functions (including the legislative, executive and judicial thinking styles), forms (including the hierarchical, oligarchic, monarchic and anarchic styles), levels (including the liberal and conservative styles), scopes (including the internal and external styles), and leaning (including the liberal and conservative styles) [14-[15].

According to Rita Borromeo Ferri, the style of thinking is in terms of how students choose a presentation, understand, and think through the math facts and their connection with the way of imagination to internal and/or external representation [8]. According to Rita Borromeo Ferri, classifications of thinking styles are visual thinking style, analytical thinking style, and integrated thinking style [16]-[18]. The two thinking styles have differences i.e. Stenberg was more in terms of information processing model whereas the Ferri was the model representation of the information [19].

Thinking styles have an important role in learning and learning as well as to obtain academic achievement especially mathematics [20]. Thinking styles are not only related to academic achievement, but also to emotional intelligence [21] and the behavior that leads to creativity [22]. Thinking styles can be measured in several ways including the awarding of the now, solving problems [23], The Thinking Style Inventory (TSI) [24], The Mathematical Thinking Scale [25], [26], one-to-one interviews, semi-structured questionnaires [27], and documentation [28].

Written test has weaknesses in determining the accuracy of students' ability [29]. Based on observation, it can be due to the presence of students' cheating, cheating answer, troubleshooting procedures in the book, and replicate the problem resolution procedures previously exemplified. An engineering assessment to obtain accurate information of students' ability is oral test. Oral test may take the form of interviews with the student one by one [30]. One-by-one interview can observe a conceptual knowledge of students in depth. It is useful for teachers to explore students' ability on a 
certain topic, so it can determine an effective learning method and corresponding ability of students.

\section{METHOD}

The objective of the research was to analyze the student's thinking styles through an oral test. The research design was descriptive research. The description was analyzed from the related interview by researcher and students during the oral tests. The subject of research was the student of Mathematics Education Department Class 6C. This class consists of 48 students divided based on the style of visual thinking, analytical or integration. The division was based on the results of a test that took the form of a one-by-one oral interview.

Research instrument was in the form of a list of question in oral test that was structured based on Curvature Theorem. Questions were associated with the reason each step to prove theorems. Questions were also developed in accordance with the students' answers. The list of the oral test questions was structured as follows:

1. Explain what the theorem means!

2. What is known by the theorem's statement?

3. What is the logical form of the theorem's statement?

4. What would theorem be proved?

5. What is the preliminary step to prove the theorem?

6. How could you redraw and what are the components of the graph? (if you used the graph)

7. Explain the reason of the steps that you have selected!

8. What is the underlying the proof?

9. What is the difference from the previous definition of curvature theorem?

10. When is the theorem used?

11. How many formulas are given in the theorem?

12. What is the difference from both formula?

The data in the form of an oral test answers were analyzed and categorized according to the characteristics of mathematical thinking styles. Analytic thinking style has a characteristic style that was modeled mathematically and worked formally on real problems. Visual thinking styles can be characterized by having students' imagination or described in the form of pictures, graphics, or sketch. In addition, visual thinking styles resolved problems in mathematical modeling cycle normatively [12]. Integrated thinking styles have a flexible characteristic in the use of visual or analytical representation [8].

The theorem and its proof were used as verbal tests of materials i.e. the Curvature Theorem. This theorem studied Vector Analysis Courses. The theorem described the curvature formula when there were vector equations with parametric equations known. The curvature theorem was as follows:
Consider a curve with vector equation $r(t)=f(t) \vec{\imath}+g(t) \vec{j}$, that is, parametric equations $x=f(t)$ and $y=g(t)$. Then,

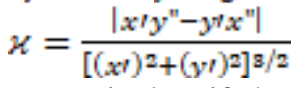

In particular, if the curve is the graph of $y=g(x)$, then

$$
x=\frac{\left\|y^{\mathrm{r}}\right\|}{\left[1+\left(y^{v}\right)^{2}\right]^{\mathrm{s} / \mathrm{s}}}
$$

\section{RESULT}

The oral test was considered on May 7 - 19, 2018. Oral test was done in two weeks using procedure that each student met researchers to carry out oral test in turn. Oral test took 30 - 45 minutes for each student. Based on the results of the oral test, students were classified based on the thinking style. Thinking styles that emerged after the oral test held showed 22 students had integrated thinking style, 14 students had visual thinking styles and 12 students had the analytic thinking style.

\section{Visual Thinking Style}

Students who had a visual thinking style, firstly used images that were available in the book Calculus 9th Edition by Varberg, Edwin Purcell and Steve Rigdon page 596. The picture has components of the curve, the tangent vector, and unit vector that create a parallel to the $\mathrm{x}$-axis and a normal vector. Students who had a visual thinking style could not redraw Picture 7 that was in the book. The conversation and oral tests were as follows:

$\begin{array}{ll}\text { Researcher } & : \text { Could you explain what the meaning } \\ & \text { of the theorem is? } \\ \text { Student } & : \text { So, from Figure } 7, \text { the proof would be } \\ & \text { started. Based on Figure } 7, \text { it retrieved } \\ & \tan \theta=\frac{d y}{d x}\end{array}$

Researcher : What would the theorem prove? What is the formula that was proven by the theorem?

$\begin{array}{ll}\text { Student } & \text { : Mmm... (silence) curvature formula } \\ \text { Researcher } & \text { : What is curvature? } \\ \text { Student } & : \text { (Drawing a curve) Curvature is a } \\ & \text { curved line and this is curvature } \\ \text { (pointed to Picture } 7 \text { especially in the } & \text { curve) } \\ \text { Researcher } & \text { : Could we draw the curvature? What } \\ & \text { is the form of curvature? } \\ \text { Student } & : \text { No, we could not, Mam. The } \\ & \text { curvature is ... mmm ... is it a number? } \\ \text { Researcher } & : \text { That's right, so the form of curvature } \\ & \text { is a number which represents how } \\ & \text { curved a curve is. Then, what is the } \\ \text { theorem? } & \end{array}$

Student $\quad$ : Vector equation in the form of $\vec{r}$ 


\begin{abstract}
Researcher : What is the vector equation?
Student : (Pointed to Picture 7 especially in tangent vector). This is the vector equation, Mam. In the form of directional line segment that drawing on the point in the curve.

Researcher : How you could determine the tangent vector?

Student : (Drawing unit tangent vector) It would be drawn from a point in the curve then draw the vector such that tangent the curve

Researcher : What about formula to determine the unit tangent vector?

Student : Mmm ... We could use the first derivative of $r$. It means that $r$ is instead of the tangent vector unit vector, but rather the position of a point on the curve.

Researcher : That's right, then what is $\varphi$ ?

Student :(Drawing) Angles formed counterclockwise from vector are made parallel to the $x$-axis towards the unit tangent vector.
\end{abstract}

The dialog shows the students answer the questions using sketches and drawings of the graph. This is in accordance to the characteristics of visual thinking styles where students represent an understanding in the form of graphs.

The students with analytic thinking style mostly used symbol, mathematical model, or mathematical language. The students also preferred explaining the proof of theorem to writing on paper. They could explain the reason of each step formally and mentioned the mathematical words. In proving theorem, students started at the reason why the theorem comes. They also could show the difficult problem that could not be solved using the first formula. Then, the students explained how to form $\varphi$ and get $\tan \varphi=\frac{y v}{x}$. They also understood why we were allowed to form $\tan \varphi=\frac{d y}{d x}$. They explained that those equations derived from the theorem of differential calculus that showed gradient.

The students who had integrated thinking style started the proof from the Picture 7 and explained each step of proof algebraically. Each of them could redraw the graph, mention the component of graph, and explain how to prove the theorem using mathematical symbol completely.

\section{CONCLUSION}

The oral test could analyze thinking style that is visual, analytic, and integrated to prove theorem. Students who had visual thinking style often drew and pointed the graph without writing and explaining it well. Most students who had analytic thinking style could explain each step to prove theorem using the reasons and sometimes write the mathematical symbol to complete the proof. The students who had integrated thinking style drew the graph and also explained each step to prove the theorem algebraically.

\section{REFERENCES}

[1] M. I. S. B. Halil Onal, "A research on Mathematical Thinking Skills: Mathematical Thinking Skills of Athletes in Individual and Team Sport," Journal of Education and Training Studies, vol. 5, no. 9, pp. 133-139, 2017.

[2] K. Ulger, "The Relationship between Creative Thinking and Critical Thinking Skills of Students," H. U. Journal of Education, vol. 4, no. 31, pp. 695-710, 2016.

[3] E. Apino, "Developing Instructional Design to Improve Mathematical Higher Order Thinking SKills of Students," Journal of Physics, pp. 1-7, 2017

[4] J. M. G. M. Benediktus Tanujaya, "The Relationship between Higher Order Thinking Skills and Academic Performance of Student in Mathematics Instruction," International Education Studies, vol. 10, no. 11, pp. 78-85, 2017.

[5] N. Aljojo, "Differences in Styles of Thinking 'in Light of Stenberg's Theory': A Case of Different Educational Levels in Saudi Arabia," Journal of Tchnology and Science Education, vol. 7, no. 3, pp. 333-346, 2017.

[6] L. Zhang, "Thinking styles and modes of thinking: implications for Education and Research," The Journal of Psychology, vol. 6, no. 136, pp. 245261, 2002.

[7] K. A. Gafoor, "Relationship of Thinking Style with Physics Achievement Among Higher Secondary Students of Kerala," Indian Educational Review, vol. 46, no. 1, pp. 51-63, 2010.

[8] Risnanosanti, "Mathematical thinking styles of undergraduate students and their achievement in Mathematics," in AIP Conference Proceedings, Yogyakarta, 2017.

[9] E. Spengenberg, "Thinking styles of Mathematics and Mathematical Literacy learners: Implication for Subject Choice," Pythagoras, vol. 3, no. 33, pp. 1-12, 2012. 
[10] A. M. a. H. Janeke, "The relationship between thinking styles and emotional intelligence: an exploratory study," South African journal of psychology, vol. 3, no. 39, pp. 357-375, 2008.

[11] A. Dikici, "Relationships between Thinking Styles and Behaviors Fostering Creativity: An Exploratory Study for the Mediating Role of Certain Demographic Traits," Educational Sciences: Theory \& Practice, vol. 1, no. 14, pp. 179-201, 2014.

[12] R. B. Ferri, "Mathematical Thinking Styles and Their Influence on Teaching and Learning Mathematics," in 12th International Congress on Mathematical Education, Seoul, 2012.
[13] A. S. Andreas Moutsios-Rentzos, "The Thinking Styles of University Mathematics Students," Acta DIdactica Napocensia, vol. 3, no. 4, pp. 1-10, 2010.

[14] A. B. N. Ersoy E., "Matematiksel dusunme olceginin gelistirilmesi. Kastamonu Egitim Dergisi (Ozel Say1).," Cilt:21, no. 4, pp. 14711486, 2012.

[15] A. M. a. A. R. Doug Clarke, "Student One-ToOne Assessment Interviews in Mathematics: A Powerful Tool for Teachers," in MAV Annual Conference, Melbourne, 2005. 